\title{
Influence of Atrophic Posterior Maxilla Ridge Height on Bone Density and Microarchitecture
}

\author{
Alberto Monje, DDS; ${ }^{\star}$ Florencio Monje, MD, PhD; ${ }^{\dagger}$ Raúl González-García, MD, PhD; \\ Fernando Suarez, DDS;* Pablo Galindo-Moreno, DDS, PhD; ${ }^{\S}$ Agustin García-Nogales, PhD; \\ Hom-Lay Wang, DDS, MS, $\mathrm{PhD}^{* *}$
}

\begin{abstract}
Purpose: There is limited evidence available on the influence of residual ridge height (RH) on bone density. Therefore, this study aimed to investigate the correlation between the atrophic posterior RH in the maxilla and its bone density as determined by microcomputed tomography $(\mu-\mathrm{CT})$.

Material and Methods: Thirty-two subjects with atrophic posterior maxilla of residual $\mathrm{RH}<8 \mathrm{~mm}$ were included in this study. A preoperative cone beam CT scan with a radiographic stent was taken for each patient. A bone core biopsy was thus obtained from the predetermined surgical site. Out of 32 biopsies, 27 were intact and sent for $\mu$-CT analysis.

Results: A statistically significant positive correlation between bone volumetric fraction (BV/TV) and RH was identified $(r=0.417, p=.03)$. A statistically significant negative correlation between trabecular pattern factor and $\mathrm{RH}$ was also found $(r=-0.415, p=.03)$. The rest of the morphometric parameters analyzed did not have any significant correlation to RH.

Conclusion: BV/TV is potentially influenced by the residual bone height at the posterior maxilla. The lesser the RH, the lower the bone quantity and quality present.
\end{abstract}

KEY WORDS: alveolar ridge augmentation, bone, dental implant, grafting, maxillary ridge augmentation

\section{INTRODUCTION}

Oral rehabilitation of the maxillary posterior region with implants often presents as a challenge for the surgeon. ${ }^{1}$ This is because of the loss of vertical bone height after tooth removal, thereby making the placement of standard length implants $(\geq 10 \mathrm{~mm})$ impossible. ${ }^{2,3}$ As such, maxillary sinus augmentation has made

${ }^{*}$ Resident, Graduate Periodontics, Department of Periodontics and Oral Medicine, University of Michigan School of Dentistry, Ann Arbor, MI, USA; †director, Oral and Maxillofacial Surgeon, CICOM, Center of Implantology, Oral and Maxillofacial Surgery, Badajoz, Spain; "head of department, Department of Biostatistics, Infanta Cristina Hospital, Badajoz, Spain; ${ }^{`}$ adjunct professor, Department of Oral Surgery and Implant Dentistry, University of Granada, Granada, Spain; 'attending surgeon, Oral and Maxillofacial Surgeon, CICOM, Center of Implantology, Oral and Maxillofacial Surgery, Badajoz, Spain; ${ }^{* *}$ program director and professor, Graduate Periodontics, Department of Periodontics and Oral Medicine, University of Michigan School of Dentistry, Ann Arbor, MI, USA

Reprint requests: Dr. Alberto Monje, Calle Juan Miró s/n, local 16-17, 06010 Badajoz, Spain; e-mail: amonjec@umich.edu

(C) 2013 Wiley Periodicals, Inc.

DOI $10.1111 /$ cid.12075 implant placement in the atrophic posterior maxilla possible. Grafting of the antral floor is achieved by elevating the Schneiderian membrane and placing graft material to promote bone formation by osteoconduction or osteoinduction. ${ }^{4,5}$ Survival rates of dental implants placed in the posterior maxilla depend on bone quality and density at the site. ${ }^{6-9}$ Hence, a thorough examination of the native bone must be performed in order to select the most favorable site for implant placement.

Microcomputed tomography $(\mu-\mathrm{CT})$ has become a well-documented method to study bone microstructures because it provides accurate threedimensional (3D) images and is time efficient ${ }^{10}$ compared with conventional histomorphometry. ${ }^{11,12}$ $\mu$-CT images are the result of differences in X-ray attenuation properties of bone, marrow spaces, and soft tissues. ${ }^{13}$ It may determine 3D bone structures in depth having a resolution of micrometer to submicrometer. ${ }^{14}$ Therefore, it allows computation of architectural metric parameters, such as bone volume, total volume, and bone surface. ${ }^{15}$ 
Bone quality is defined by several micromorphometric parameters and also by clinical assessment. Lekholm and $\mathrm{Zarb}^{16}$ classified bone quality and volume in four groups considering type I bone as dense cortical bone, whereas type IV referred to cancellous bone. Subsequently, Misch proposed a classification based on the location, composition, and measurable density reading by $\mathrm{CT} .{ }^{17}$ According to this classification, the posterior maxilla is composed by D3-D4 bone due to the porous thin layer of cortical bone and fine trabecular bone underneath the cortical bone. Aksoy and colleagues evaluated the bone density values of the maxilla. They found lower bone volumetric fraction (BV/TV) values in the maxilla when they analyzed all the maxillary sites together. ${ }^{18}$ Ulm and coworkers showed a mean total bone volume in molar areas as 23.4 and $17.1 \%$ for males and females, respectively. ${ }^{19}$ Similarly, Trisi and Rao in a histomorphometric study demonstrated that D4 bone had $28.28 \%$ of trabecular bone volume. ${ }^{20}$ There is, however, no study assessing the influence of residual ridge height (RH) on bone microarchitecture in the atrophic posterior maxilla.

Therefore, this study aimed to analyze the relationship between bone density obtained by $\mu-\mathrm{CT}$ and $\mathrm{RH}$ in the atrophic posterior maxilla. It is hypothesized that the lower the $\mathrm{RH}$, the less dense the bone and hence primary implant stability might not be optimal.

\section{MATERIAL AND METHODS}

The present study was independently reviewed and approved by the local ethics committee of the University Hospital Infanta Cristina (Badajoz, Spain). Written informed consent was obtained from each subject during the screening visit. Patients between 18 and 80 years old, nonsmokers, with no infectious diseases at time of implant insertion, and no diseases or conditions known to alter bone metabolism, e.g., osteoporosis, renal disease, oncologic disease, or disturbance of the calcium metabolism, were considered for this study. Patients must also be partially edentulous with an atrophic posterior maxilla and a $\mathrm{RH}$ of $<8 \mathrm{~mm}$, thus requiring sinus augmentation for placement of standard implants. They should have adequate oral hygiene and sufficient bone width to place at least a 3.75-mmdiameter dental implant. Patients who were pregnant, smokers, taking medications known to modify bone metabolism, or had taken antibiotics for more than
2 weeks in the past 3 months were excluded from this study.

A total of 32 subjects, 16 males and 16 females with a mean age of $56 \pm 11.4$ years old, were enrolled in this study. The average $\mathrm{RH}$ measured was $6.06 \pm 3.26$ (range from $2.8 \mathrm{~mm}$ up to $8 \mathrm{~mm}$ ). One site per patient was randomly selected for bone core biopsy at the site planned for implant placement. Five out of 32 biopsies obtained could not be processed because the specimens broke when removing them from the trephine.

\section{Preoperative Cone Beam CT (CBCT) Examination}

A customized acrylic resin template with a 2-mmdiameter metal rod placed at the randomly selected site of implant placement was fitted on each patient prior to the acquisition of the CBCT image. The CBCT images of the patients' maxillary arches were acquired by i-CAT Model 17-19 (Imaging Sciences International LLC, Hatfield, PA, USA). The imaging parameters were set at $120 \mathrm{kVp}, 18.66 \mathrm{~mA} \mathrm{~s}$, scan time 20 seconds, resolution $0.4 \mathrm{~mm}$, and a field of view that varied based on the scanned region. The $\mathrm{RH}$ at the planned site for implant placement was measured using i-CAT Vision (Imaging Sciences International LLC) (Figure 1).

\section{Surgical Procedure}

Each subject was given $1000 \mathrm{mg}$ amoxicillin or $600 \mathrm{mg}$ clindamycin 1 hour prior to surgery. Under intravenous

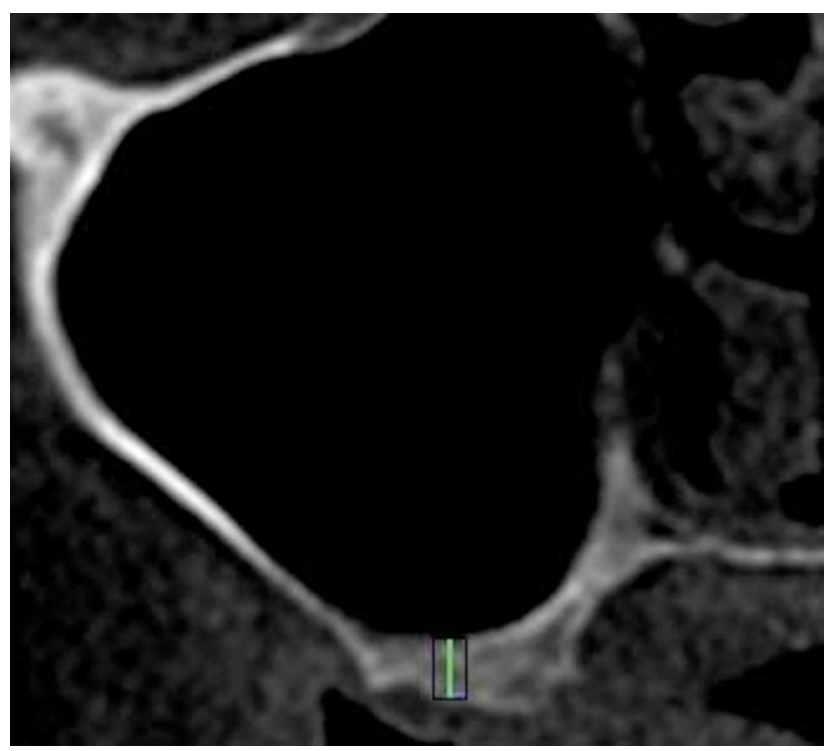

Figure 1 Perpendicular line drawn from the midpoint of the bottom to the top of the rectangle plotted in the i-CAT. 
sedation and local anesthesia, a crestal incision was made. Subsequently, a full-thickness flap was reflected to expose the lateral wall of the sinus. ${ }^{21}$ The sinus wall and membrane were elevated. The customized stent was placed and secured in the proper position. A 2-mmdiameter bone core sample was trephined from the residual ridge following the direction of the metal rod on the customized stent. The sinus cavities were grafted with mineralized cancellous allograft (Puros, Zimmer Dental Inc., Carlsbad, CA, USA). Implant site preparation was performed and Nobel Speedy Groovy (Nobel Biocare AB, Goteborg, Sweden) implants were inserted with primary implant stability. Tension-free primary wound closure was achieved at the surgical sites. Nine months after the simultaneous sinus augmentation and implant placement surgery, a second-stage surgery was performed in all subjects.

\section{$\mu$-CT Analysis}

The bone core biopsies were preserved at $-20^{\circ} \mathrm{C}$ and scanned with a high-resolution $\mu$-CT SkyScan $1172^{\circledR}$ (Bruker-MicroCT, Kartuizersweg, Kontich, Belgium) in $100 \mathrm{~V}$ and $100 \mu \mathrm{A}$. The exposure time was 450 milliseconds. Images were reconstructed by a software (Nrecon ${ }^{\circledR}$, SkyScan $\mathrm{NV}^{\circledR}$, Aartselaar, Belgium), which used the modified algorithm described by Feldkamp et al. ${ }^{22}$ to obtain the axial sections of the specimen (Figures 2 and 3 ). The morphometric variables analyzed were the following:

$1 \mathrm{BV} / \mathrm{TV}$ refers to the total amount of bone present in relation to the analyzed bone volume. It is a parameter widely used in pathologies that alter bone turnover as it reflects perfectly bone gain/loss. It indicates the fraction of a given volume of interest occupied by mineralized tissue. Therefore, implant anchoring at implant placement will rely mainly on this parameter.

2 Bone surface density is the relationship between the overall trabecular bone surface and the bone volume of mineralized bone.

3 Bone specific surface analyzes the relation between the trabecular bone surface and the mineralized bone. In a 3D image, it directly measures distance in space.

4 Trabecular thickness determines bone fill as well as the mean thickness of the osseous structures.

5 Trabecular spacing (Tb.Sp) detects marrow spaces and thus should be correlated to BV/TV: the more BV/TV, the less Tb.Sp. ${ }^{23}$ Therefore, this parameter determines inverse bone density.

6 Trabecular number implies the number of times a trabecular structure is crossed per unit length in a randomly selected way.

7 Bone quality is determined by direct nonmetric parameters. Trabecular pattern factor (Tb.Pf) describes quantitatively trabecular connectivity. ${ }^{24}$ It is an inverse connectivity index. Therefore, concavity of the trabecular surfaces implies connectivity, whereas convexity means isolated and misconnected structures.

8 Structural model index determines the relative presence of either platelike or rodlike trabeculae. It is defined in a range of 0 to 3 , where closer to 0 corresponds to and ideal plate and 3 to an ideal cylinder. ${ }^{25}$ Normally, platelike are associated to a higher osseous stiffness.

9 The degree of anisotropy ( $D A)$ measures the presence or absence of structures lined in a specific direction. Biopsies analyzed with a high DA indicate that the trabeculae are oriented in the same

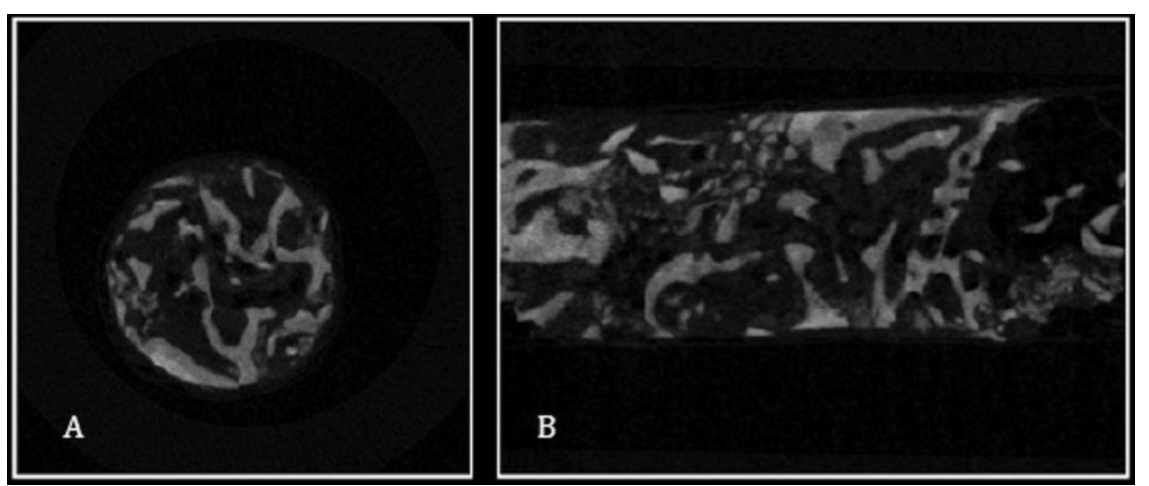

Figure 2 Two-dimensional microcomputed tomography images of bone core \#18. (A) Transversal view of the biopsy. (B) Sagittal view of the biopsy. 


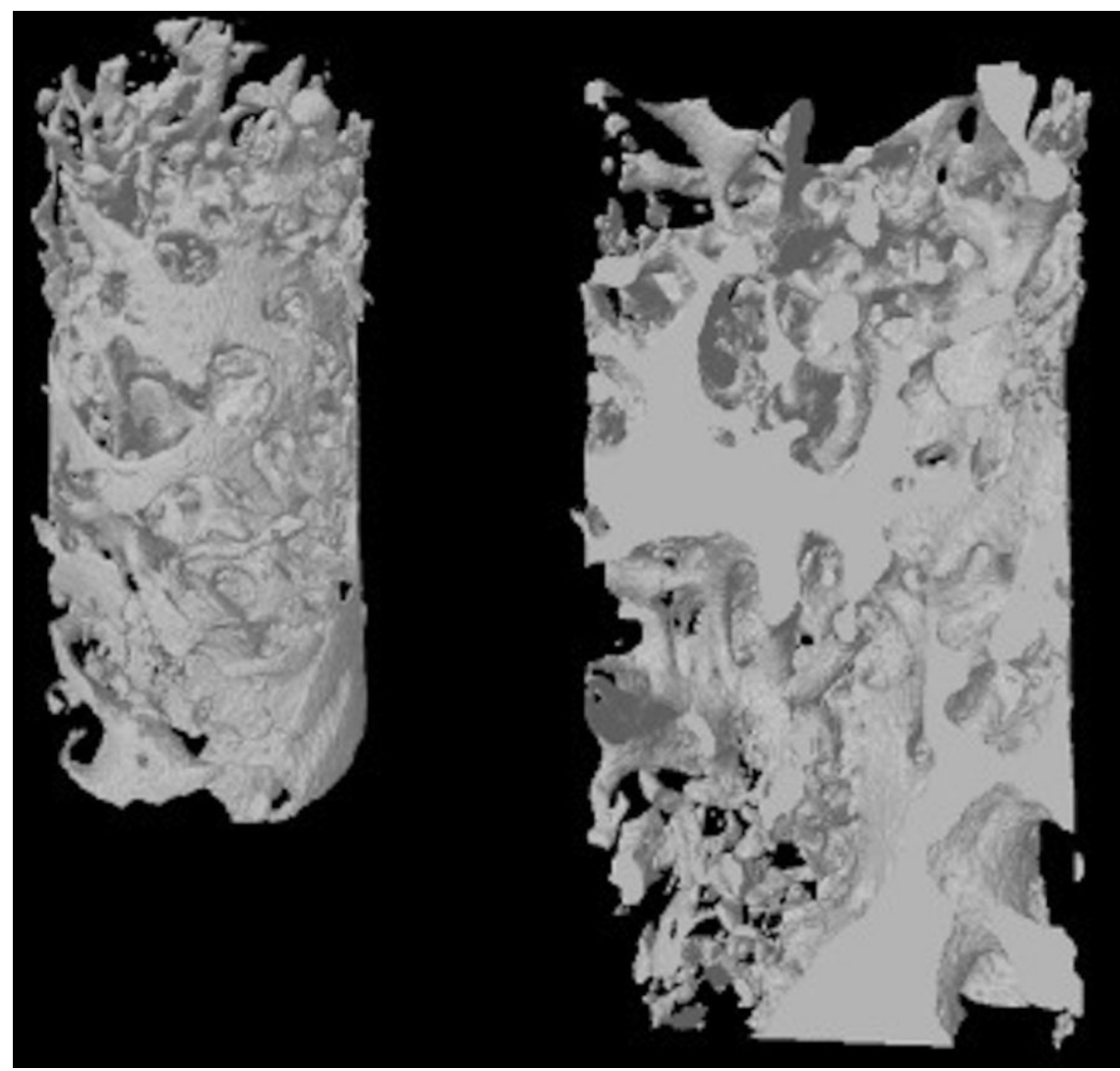

Figure 3 Three-dimensional microcomputed tomography image of bone core biopsy \#18.

direction. Mechanical anisotropy means that the mechanical properties are different for measuring different directions in the same sample. ${ }^{26}$ Therefore, DA is probably the most important determinant of biomechanical strength. ${ }^{27}$

10 Volumetric bone mineral density compares between the attenuation coefficients of two hydroxyapatite patterns of known density $\left(250\right.$ and $\left.750 \mathrm{mg} / \mathrm{cm}^{3}\right)$. This is an areal density and not a true volume density as it has a dependency on bone size. ${ }^{28}$

\section{Statistical Analysis}

Data analysis was performed with the statistical software STATISTICA version 7.1 (StatSoft ${ }^{\circledR}$, Tulsa, OK, USA). Linear relationship between morphometric parameters and $\mathrm{RH}$ were analyzed using the Pearson's correlation coefficient.

\section{RESULTS}

Mean values for each variable in relation to the microstructure of bone and RH were shown in Table 1.
Correlations between morphometric parameters of each biopsy and RH were displayed in Table 2. Statistically significant positive correlation between BV/TV and RH $(r=0.417, p=.03)$ was identified (Figure 4), while a statistically significant negative correlation between $\mathrm{Tb}$.Pf and RH $(r=-0.415, p=.03)$ was found (Figure 5). The other morphometric parameters studied were not correlated to RH.

\section{DISCUSSION}

Primary or mechanical implant stability, as determined by availability of peri-implant bone, is important for successful osseointegration. ${ }^{6}$ Bone quality has been shown to be a key factor in predicting success in implant therapy. ${ }^{29}$ Therefore, in poor bone quality, other factors, such as implant macrodesign and microdesign and drilling and loading protocols, must be taken into consideration to envisage implant success. Centripetal resorption of the alveolar process in the posterior maxilla often results in insufficient bone volume and quality; thus, it is a challenge to achieve primary implant stability in the 


\begin{tabular}{|c|c|c|c|c|c|c|c|c|c|c|c|}
\hline $\begin{array}{l}\text { Biopsy } \\
\text { Number }\end{array}$ & $\mathrm{RH}$ & BV/TV & $\mathrm{BS} / \mathrm{BV}$ & $\mathrm{BS} / \mathrm{TV}$ & Tb.Th & Tb.Sp & Tb.N & Tb.Pf & SMI & DA & vBMD \\
\hline 1 & 5.6 & 36.53 & 20.82 & 7.61 & 0.20 & 0.26 & 1.85 & 9.19 & 2.59 & 1.61 & 471.80 \\
\hline 2 & 7.7 & 35.95 & 17.40 & 6.26 & 0.22 & 0.40 & 1.56 & 4.54 & 1.76 & 3.32 & 489.60 \\
\hline 3 & 4.8 & 42.00 & 21.17 & 8.89 & 0.19 & 0.27 & 2.12 & 5.83 & 1.96 & 1.32 & 568.72 \\
\hline 4 & 4.8 & 44.84 & 14.71 & 6.60 & 0.28 & 0.36 & 1.55 & 4.15 & 1.85 & 1.64 & 771.38 \\
\hline 5 & 4.8 & 24.97 & 24.62 & 6.15 & 0.15 & 0.41 & 1.63 & 6.36 & 1.62 & 4.73 & 387.72 \\
\hline 6 & 2.8 & 19.19 & 27.50 & 5.28 & 0.14 & 0.39 & 1.33 & 11.18 & 2.21 & 1.74 & 265.88 \\
\hline 7 & 7.7 & 29.04 & 25.76 & 7.48 & 0.17 & 0.29 & 1.68 & 8.75 & 2.16 & 1.57 & 407.09 \\
\hline 8 & 6.4 & 26.74 & 19.52 & 5.22 & 0.22 & 0.43 & 1.17 & 8.03 & 2.52 & 2.11 & 356.24 \\
\hline 9 & 6.5 & 28.36 & 26.69 & 7.57 & 0.13 & 0.35 & 2.06 & 4.50 & 1.17 & 2.30 & 499.62 \\
\hline 10 & 5.26 & 21.49 & 31.09 & 6.68 & 0.14 & 0.32 & 1.52 & 10.84 & 2.24 & 1.49 & 315.25 \\
\hline 11 & 6.25 & 39.29 & 18.07 & 7.10 & 0.20 & 0.34 & 1.88 & 0.64 & 0.72 & 0.85 & 398.78 \\
\hline 12 & 8 & 53.85 & 25.22 & 13.58 & 0.16 & 0.14 & 3.21 & 0.43 & 0.98 & 0.29 & 606.55 \\
\hline 13 & 7.25 & 26.05 & 25.01 & 6.51 & 0.14 & 0.40 & 1.76 & 6.68 & 1.58 & 0.71 & 312.54 \\
\hline 14 & 7 & 21.11 & 31.32 & 6.61 & 0.12 & 0.50 & 1.73 & 6.74 & 1.46 & 0.61 & 299.35 \\
\hline 15 & 7.77 & 29.70 & 26.16 & 7.77 & 0.17 & 0.24 & 1.69 & 12.01 & 2.73 & 0.37 & 424.50 \\
\hline 16 & 7 & 48.78 & 19.56 & 9.54 & 0.22 & 0.21 & 2.14 & 4.10 & 1.80 & 0.68 & 616.04 \\
\hline 17 & 7.2 & 32.31 & 20.52 & 6.63 & 0.23 & 0.30 & 1.38 & 8.10 & 2.54 & 2.33 & 412.21 \\
\hline 18 & 4.02 & 23.60 & 31.26 & 7.38 & 0.12 & 0.33 & 1.93 & 8.61 & 1.77 & 1.34 & 434.96 \\
\hline 19 & 7.5 & 54.80 & 20.61 & 11.30 & 0.18 & 0.20 & 3.03 & 3.32 & 0.01 & 1.18 & 921.69 \\
\hline 20 & 6.25 & 21.92 & 28.95 & 6.35 & 0.12 & 0.40 & 1.76 & 8.75 & 1.80 & 1.83 & 322.28 \\
\hline 21 & 7.25 & 35.71 & 21.86 & 7.80 & 0.17 & 0.31 & 2.07 & 3.25 & 1.29 & 1.42 & 465.65 \\
\hline 22 & 5.5 & 37.62 & 23.86 & 8.98 & 0.15 & 0.24 & 2.46 & 3.55 & 1.19 & 1.86 & 465.20 \\
\hline 23 & 7.2 & 29.96 & 17.57 & 5.26 & 0.20 & 0.49 & 1.47 & 5.79 & 2.12 & 1.59 & 357.05 \\
\hline 24 & 4.01 & 18.95 & 28.26 & 5.35 & 0.13 & 0.38 & 1.36 & 11.44 & 2.27 & 1.46 & 285.37 \\
\hline 25 & 5.76 & 26.59 & 31.64 & 8.41 & 0.15 & 0.23 & 1.72 & 14.07 & 2.79 & 1.42 & 400.11 \\
\hline 26 & 7.7 & 38.78 & 21.22 & 8.23 & 0.18 & 0.32 & 2.10 & 3.56 & 1.43 & 0.47 & 482.07 \\
\hline 27 & 6.5 & 39.35 & 18.15 & 7.14 & 0.22 & 0.30 & 1.79 & 4.96 & 1.90 & 0.53 & 463.05 \\
\hline Mean & 6.06 & 31.42 & 23.15 & 7.27 & 0.16 & 0.31 & 1.8 & 5.39 & 1.48 & 1.25 & 432.47 \\
\hline SD & 3.26 & 10.12 & 4.87 & 1.85 & 0.41 & 0.87 & 0.46 & 3.45 & 0.64 & 0.94 & 147.50 \\
\hline
\end{tabular}

$\mathrm{BS} / \mathrm{BV}=$ bone specific surface; $\mathrm{BS} / \mathrm{TV}=$ bone surface density; BV/TV = bone volumetric fraction; $\mathrm{DA}=$ degree of anisotropy; $\mathrm{SD}=$ standard deviation; $\mathrm{SMI}=$ structural model index; Tb.N = trabecular number; Tb.Pf $=$ trabecular pattern factor; $\mathrm{Tb} . \mathrm{Sp}=$ trabecular spacing; $\mathrm{Tb} . \mathrm{Th}=\mathrm{trabecular}$ thickness; $\operatorname{vBMD}=$ volumetric bone mineral density.

posterior maxillary regions. Thus, sinus augmentation is necessary to increase alveolar bone height for primary implant stability.

In the past, the common practice is to perform sinus augmentation and allow the bone graft to mature over a period of 4 to 6 months before implant placement. The current trend is to perform simultaneous sinus augmentation and implant placement. Therefore, the residual $\mathrm{RH}$ is a key determinant of primary implant stability and the success of osseointegration. As such, residual RHs of 4 to $6 \mathrm{~mm}$ have been proposed as the minimum height required for simultaneous sinus augmentation and implant placement. ${ }^{30,31}$ However, recent reports on the migration of dental implants into the maxillary sinus after simultaneous sinus augmentation and implant placement $\mathrm{t}^{32-35}$ have sparked concerns on the safety of the proposed minimum residual $\mathrm{RH}$ of 4 to $6 \mathrm{~mm}$. In a recent study, an increase in incidence of implant migration into the maxillary sinus was found to be associated with a $\mathrm{RH}$ of 5 to $7 \mathrm{~mm}$. This finding might prompt clinicians to perform less invasive procedures in the atrophic posterior maxilla. ${ }^{35}$

Results from this study showed that BV/TV was clearly influenced by RH. Therefore, extremely resorbed 


\begin{tabular}{llc}
$\begin{array}{l}\text { TABLE } 2 \text { Pearson's Correlation of Ridge Height }(\mathbf{R H}) \\
\text { and Morphometric Parameters Analyzed by } \mu \text {-CT }\end{array}$ \\
Morphometric & \multicolumn{2}{c}{ RH } \\
Parameter & $r$ & 0.417 \\
\hline BV/TV & $p$-value & .03 \\
& $r$ & 0.285 \\
BS/BV & $p$-value & .149 \\
& $r$ & 0.377 \\
BS/TV & $p$-value & .051 \\
& $r$ & 0.224 \\
Tb.Th & $p$-value & .26 \\
& $r$ & 0.191 \\
Tb.Sp & $p$-value & .338 \\
& $r$ & 0.342 \\
Tb.N & $p$-value & .08 \\
& $r$ & 0.415 \\
Tb.Pf & $p$-value & .031 \\
& $r$ & 0.251 \\
SMI & $p$-value & .205 \\
& $r$ & 0.283 \\
DA & $p$-value & .152 \\
& $r$ & 0.239 \\
vBMD & $p$-value & .229 \\
& & \\
& &
\end{tabular}

$\mathrm{BS} / \mathrm{BV}=$ bone specific surface; $\mathrm{BS} / \mathrm{TV}=$ bone surface density; $\mathrm{BV} / \mathrm{TV}=$ bone volumetric fraction; $\mathrm{DA}=$ degree of anisotropy; $\mu$-CT = microcomputed tomography; $\mathrm{SMI}=$ structural model index; $\mathrm{Tb} . \mathrm{N}=$ trabecular number; $\mathrm{Tb} . \mathrm{Pf}=$ trabecular pattern factor; $\mathrm{Tb} . \mathrm{Sp}=$ trabecular spacing; $\mathrm{Tb} . \mathrm{Th}=$ trabecular thickness; $\mathrm{vBMD}=$ volumetric bone mineral density. ridges are not the best candidates for simultaneous sinus augmentation and implant placement. Alternatively, if the RH is sufficient, an osteotome sinus lift can be performed to retain and condense the available periimplant bone so that denser bone surrounds the implant fixture providing added primary stability. ${ }^{36}$ The impact of $\mathrm{RH}$ on implant stability and survival has been the subject of investigation,,$^{37,38}$ and it can be assumed that bone quality of the residual ridge influenced bone formation; hence, it might dictate how long the site should heal prior to loading. However, this concept is up for contention as other authors have reported that $\mathrm{RH}$ did not appear to influence the maturation and consolidation of an allograft in the maxillary sinus. ${ }^{39}$

Over the years, several classifications have attempted to describe and categorize the morphology of the posterior maxilla. These classifications aimed to improve diagnosis and treatment planning. Initially, Misch in 1987 developed a classification with four groups and two subdivisions, ranging from $>12$ to $<5 \mathrm{~mm}$ of $\mathrm{RH}$ and from 2.5 to $5 \mathrm{~mm}$ of bone width. In addition, several thresholds were established for treatment planning. ${ }^{40}$ Cawood and Howell in 1988 classified the edentulous jaws. They reported on anatomical variances found in the maxilla and mandible after tooth extraction, with the changes being more pronounced in the maxilla. Hence, a classification from class I (dentate

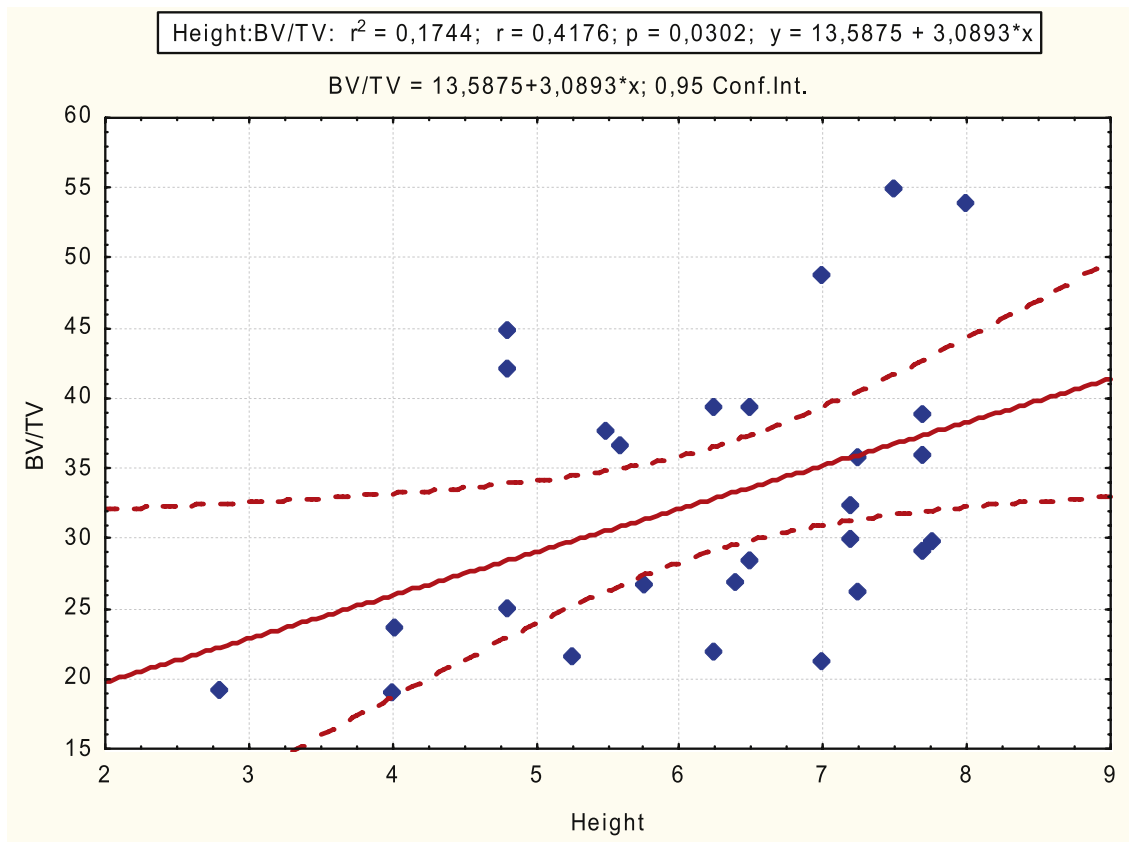

Figure 4 Correlation between bone volumetric fraction (BV/TV) and ridge height. 


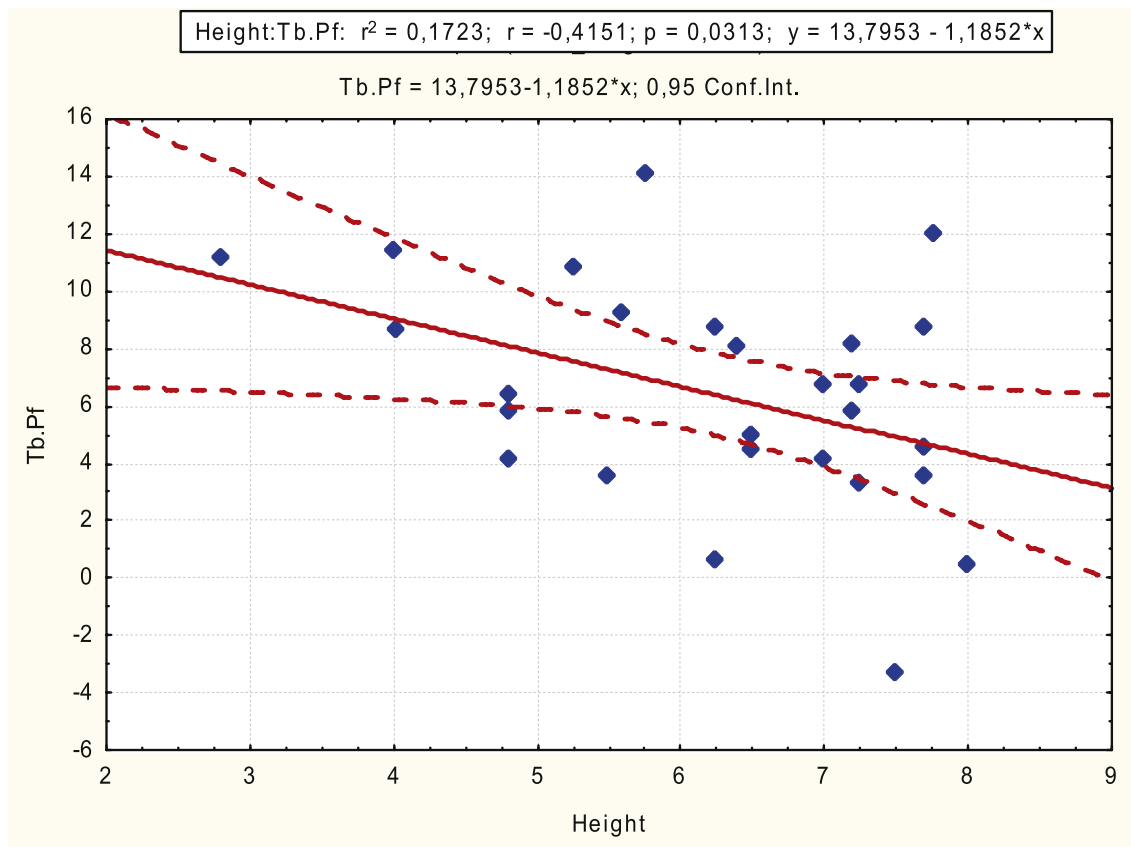

Figure 5 Correlation between trabecular pattern factor (Tb.Pf) and ridge height.

jaw) to class VI (depressed ridge form with evident basilar loss) was proposed to establish a starting point for new research in this area. ${ }^{41}$ Years later, Cawood and Howell proposed a variation of the existing classifica$\operatorname{tion}^{41}$; however, in this classification, the cementoenamel junction was used as a landmark for measuring the alveolar ridge. ${ }^{42}$ Recently, Wang and Katranji came out with the $\mathrm{ABC}$ classification for atrophic maxilla and provided a guideline for implant therapy in the posterior maxilla. ${ }^{43}$ All the above-mentioned classifications ${ }^{16,41-43}$ were aimed to facilitate treatment planning according to the remaining $\mathrm{RH}$ in the posterior maxilla due to the importance of obtaining implant primary stability upon implant insertion.

The findings from this study concurred with above-proposed treatment regimens as less BV/TV was present when there was less $\mathrm{RH}$, more difficulty could be expected when attempting to achieve primary implant stability. ${ }^{37}$ In addition, the present study showed that bone microarchitecture and density in the resorbed ridge were lower than the nonresorbed posterior maxilla. This was in agreement with the results reported by Ulm and coworkers ${ }^{19}$ and Trisi and Rao. ${ }^{20}$ The nonresorbed posterior maxilla, on the other hand, had higher quantities of mineralized tissue, ranging from $45.7 \pm 7.9^{44}$ to $47.4 \pm 1.8 \%{ }^{45}$ Therefore, assuming that implant primary stability plays the major role in future osseointegration and that bone density represents the most important determinant of primary stability in the posterior maxilla, ${ }^{46}$ clinicians should bear in mind that the lesser the RH, the less dense the bone in the posterior maxilla. Hence, a thorough treatment plan evaluating the timing of implant placement, loading protocol, and sinus elevation technique must be determined prior to the surgery in order to avoid complications such as implant migration to the maxillary sinus or early implant failure.

Within the limitation of this study, the following conclusions can be drawn: BV/TV was positively influenced by the height of the posterior atrophied maxilla and Tb.Pf was negatively correlated with $\mathrm{RH}$ in the posterior maxilla.

\section{ACKNOWLEDGMENTS}

The authors want to thank FEDICOM Foundation (Foundation for the Study of Implantology, Oral and Maxillofacial Surgery), Badajoz, Spain, for financial support. Also, they want to thank Ms. Purificación Barragán, Center of Implantology, Oral and Maxillofacial Surgery (CICOM), Badajoz, Spain, for her valuable help in order to collect and organize the data included in this study and Dr. Jia-Hui Fu (Assistant Professor, Department of Periodontics, Faculty of Dentistry, National University of Singapore, Singapore) for editing this manuscript. A.G.-N. was supported by the Spanish Ministerio de Ciencia e Innovación 
under the project MTM2010-16845 and the Junta de Extremadura Autonomous Government under the grant GR10064.

\section{REFERENCES}

1. Pietrokovski J, Massler M. Alveolar ridge resorption following tooth extraction. J Prosthet Dent 1967; 17:21-27.

2. Monje A, Chan HL, Fu JH, Suarez F, Galindo-Moreno P, Wang HL. Are short dental implants $(<10 \mathrm{~mm})$ effective? A meta-analysis on prospective clinical trials. J Periodontol 2012. doi:10.1902/jop.2012.120328

3. Pommer B, Frantal S, Willer J, Posch M, Watzek G, Tepper G. Impact of dental implant length on early failure rates: a meta-analysis of observational studies. J Clin Periodontol 2011; 38:856-863.

4. Boyne PJ, Marx RE, Nevins M, et al. A feasibility study evaluating rhBMP-2/absorbable collagen sponge for maxillary sinus floor augmentation. Int J Periodontics Restorative Dent 1997; 17:11-25.

5. Galindo-Moreno P, Avila G, Fernandez-Barbero JE, Mesa F, O'Valle-Ravassa F, Wang HL. Clinical and histologic comparison of two different composite grafts for sinus augmentation: a pilot clinical trial. Clin Oral Implants Res 2008; 19:755-759.

6. Misch CE, Hoar J, Beck G, Hazen R, Misch CM. A bone quality-based implant system: a preliminary report of stage I \& stage II. Implant Dent 1998; 7:35-42.

7. Friberg B, Jemt T, Lekholm U. Early failures in 4,641 consecutively placed Branemark dental implants: a study from stage 1 surgery to the connection of completed prostheses. Int J Oral Maxillofac Implants 1991; 6:142-146.

8. Engquist B, Bergendal T, Kallus T, Linden U. A retrospective multicenter evaluation of osseointegrated implants supporting overdentures. Int J Oral Maxillofac Implants 1988; 3:129-134.

9. Jaffin RA, Berman CL. The excessive loss of Branemark fixtures in type IV bone: a 5-year analysis. J Periodontol 1991; $62: 2-4$.

10. Rebaudi A, Koller B, Laib A, Trisi P. Microcomputed tomographic analysis of the peri-implant bone. Int J Periodontics Restorative Dent 2004; 24:316-325.

11. Zou W, Hunter N, Swain MV. Application of polychromatic microCT for mineral density determination. J Dent Res 2011; 90:18-30.

12. Gonzalez-Garcia R, Monje F. Is micro-computed tomography reliable to determine the microstructure of the maxillary alveolar bone? Clin Oral Implants Res 2012. doi:10.1111/ j.1600-0501.2012.02478.x

13. Burghardt AJ, Issever AS, Schwartz AV, et al. High-resolution peripheral quantitative computed tomographic imaging of cortical and trabecular bone microarchitecture in patients with type 2 diabetes mellitus. J Clin Endocrinol Metab 2010; 95:5045-5055.

14. Bonse U, Busch F. X-ray computed microtomography (microCT) using synchrotron radiation (SR). Prog Biophys Mol Biol 1996; 65:133-169.

15. Sukovic P. Cone beam computed tomography in craniofacial imaging. Orthod Craniofac Res 2003; 6 (Suppl 1):31-36. Discussion 179-182.

16. Lekholm U, Zarb GA. Patient selection and preparation. In: Branemark PI, Zarb GA, Albrektsson T, eds. Tissueintegrated prostheses: osseointegration in clinical dentistry. Chicago, IL: Quintessence, 1985:199-209.

17. Misch CE. Bone classification, training keys to implant success. Dent Today 1989; 8:39-44.

18. Aksoy U, Eratalay K, Tozum TF. The possible association among bone density values, resonance frequency measurements, tactile sense, and histomorphometric evaluations of dental implant osteotomy sites: a preliminary study. Implant Dent 2009; 18:316-325.

19. Ulm C, Kneissel M, Schedle A, et al. Characteristic features of trabecular bone in edentulous maxillae. Clin Oral Implants Res 1999; 10:459-467.

20. Trisi P, Rao W. Bone classification: clinicalhistomorphometric comparison. Clin Oral Implants Res 1999; 10:1-7.

21. Tatum H Jr. Maxillary and sinus implant reconstructions. Dental clinics of North America. 1986; 30:207-229.

22. Feldkamp LA, Goldstein SA, Parfitt AM, Jesion G, Kleerekoper M. The direct examination of threedimensional bone architecture in vitro by computed tomography. J Bone Miner Res 1989; 4:3-11.

23. Parfitt AM. Bone histomorphometry: proposed system for standardization of nomenclature, symbols, and units. Calcif Tissue Int 1988; 42:284-286.

24. Hahn M, Vogel M, Pompesius-Kempa M, Delling G. Trabecular bone pattern factor - a new parameter for simple quantification of bone microarchitecture. Bone 1992; 13: 327-330.

25. Hildebrand T, Ruegsegger P. Quantification of bone microarchitecture with the structure model index. Comput Methods Biomech Biomed Engin 1997; 1:15-23.

26. Currey JD. The many adaptations of bone. J Biomech 2003; 36:1487-1495.

27. Odgaard A, Gundersen HJ. Quantification of connectivity in cancellous bone, with special emphasis on 3-D reconstructions. Bone 1993; 14:173-182.

28. Compston JE. Bone density: BMC, BMD, or corrected BMD? Bone 1995; 16:5-7.

29. Molly L. Bone density and primary stability in implant therapy. Clin Oral Implants Res 2006; 17 (Suppl 2):124135.

30. Nkenke E, Stelzle F. Clinical outcomes of sinus floor augmentation for implant placement using autogenous bone or 
bone substitutes: a systematic review. Clin Oral Implants Res 2009; 20 (Suppl 4):124-133.

31. Misch CE, Qu Z, Bidez MW. Mechanical properties of trabecular bone in the human mandible: implications for dental implant treatment planning and surgical placement. J Oral Maxillofac Surg 1999; 57:700-706. Discussion 706-708.

32. Gonzalez-Garcia R, Monje F. The reliability of cone-beam computed tomography to assess bone density at dental implant recipient sites: a histomorphometric analysis by micro-CT. Clin Oral Implants Res 2012. doi:10.1111/j.16000501.2011.02390.x

33. Ridaura-Ruiz L, Figueiredo R, Guinot-Moya R, et al. Accidental displacement of dental implants into the maxillary sinus: a report of nine cases. Clin Implant Dent Relat Res 2009; 11 (Suppl 1):e38-e45.

34. Chiapasco M, Felisati G, Maccari A, Borloni R, Gatti F, Di Leo F. The management of complications following displacement of oral implants in the paranasal sinuses: a multicenter clinical report and proposed treatment protocols. Int J Oral Maxillofac Surg 2009; 38:1273-1278.

35. Galindo-Moreno P, Padial-Molina M, Avila G, Rios HF, Hernandez-Cortes P, Wang HL. Complications associated with implant migration into the maxillary sinus cavity. Clin Oral Implants Res 2012; 23:1152-1160.

36. Summers RB. A new concept in maxillary implant surgery: the osteotome technique. Compendium 1994; 15:152. 154156, 158 passim; quiz 162.

37. Rios HF, Avila G, Galindo P, Bratu E, Wang HL. The influence of remaining alveolar bone upon lateral window sinus augmentation implant survival. Implant Dent 2009; 18: 402-412.

38. Urban IA, Lozada JL. A prospective study of implants placed in augmented sinuses with minimal and moderate residual crestal bone: results after 1 to 5 years. Int J Oral Maxillofac Implants 2010; 25:1203-1212.

39. Avila-Ortiz G, Neiva R, Galindo-Moreno P, Rudek I, Benavides E, Wang HL. Analysis of the influence of residual alveolar bone height on sinus augmentation outcomes. Clin Oral Implants Res 2012; 23:1082-1088.

40. Misch CE. Maxillary sinus augmentation for endosteal implants: organized alternative treatment plans. Int J Oral Implantol 1987; 4:49-58.

41. Cawood JI, Howell RA. A classification of the edentulous jaws. Int J Oral Maxillofac Surg 1988; 17:232-236.

42. Simion M, Fontana F, Rasperini G, Maiorana C. Long-term evaluation of osseointegrated implants placed in sites augmented with sinus floor elevation associated with vertical ridge augmentation: a retrospective study of 38 consecutive implants with 1- to 7-year follow-up. Int J Periodontics Restorative Dent 2004; 24:208-221.

43. Wang HL, Katranji A. ABC sinus augmentation classification. Int J Periodontics Restorative Dent 2008; 28:383-389.

44. Galindo-Moreno P, Moreno-Riestra I, Avila G, et al. Histomorphometric comparison of maxillary pristine bone and composite bone graft biopsies obtained after sinus augmentation. Clin Oral Implants Res 2010; 21: 122-128.

45. Lindhe J, Bressan E, Cecchinato D, Corra E, Toia M, Liljenberg B. Bone tissue in different parts of the edentulous maxilla and mandible. Clin Oral Implants Res 2013. doi:10.1111/clr.12064

46. Pommer B, Hof M, Fadler A, Gahleitner A, Watzek G, Watzak G. Primary implant stability in the atrophic sinus floor of human cadaver maxillae: impact of residual ridge height, bone density, and implant diameter. Clin Oral Implants Res 2012. doi:10.1111/clr.12071 